\title{
Splitting tensile test for fibre reinforced concrete
}

\author{
E. Denneman ${ }^{1,2}$, E.P. Kearsley ${ }^{2}$, A.T. Visser ${ }^{2}$
}

(1) CSIR Built Environment, Meiring Naude road, Pretoria, South Africa

Phone +27128412933

Fax +27128412081

Email: edenneman@csir.co.za

www.csir.co.za

(2) University of Pretoria, Hillcrest, Pretoria, South Africa

\begin{abstract}
:
The splitting tensile test is a much used method to determine the tensile strength of concrete. The conventional test procedure is known to have a number of limitations related to size effect and boundary conditions. Furthermore, it has been reported to be impossible to determine the tensile strength of Fibre Reinforced Concrete (FRC) using the standard splitting tensile test method. The objective of this paper is to present a methodology to obtain a close estimate of the true tensile strength of FRC from an adjusted tensile splitting test procedure. Splitting tests were performed on cylindrical specimens of four FRC mixes. The transversal deformation perpendicular to the load direction was recorded during the tests. The experimental load-deformation curves thus obtained have two peaks, an initial one as a result of the tensile stresses at the centre of the specimen and a second peak due to secondary cracking outside the loading axis. The tensile strength can be calculated from the first peak which represents the elastic limit state for the material. The method is validated through numerical simulation of the splitting tests using a cohesive crack approach. It is concluded that it is possible to obtain a close estimate of the true tensile strength of FRC using the procedure developed in the paper.
\end{abstract}

Keywords:

Fibre reinforced concrete, Tensile strength, Fracture mechanics

Abbreviations:

FRC

Fibre Reinforced Concrete

LVDT

Linear Variable Displacement Transducer 


\section{Introduction}

Tensile strength $\left(f_{t}\right)$ is a key material parameter in the analysis of concrete structures. It is generally determined using either a direct tensile test or splitting tensile test setup. Both tests are simple in concept, but have proven quite complicated to run in such a way that reliable results, independent of specimen size and boundary conditions, are obtained. This is especially true when the aim is to obtain a reliable measure of $f_{t}$ for Fibre Reinforced Concrete (FRC).

The complexity of the direct tensile test concerns mainly the selection of specimen size. Bažant [1] points out that if a small specimen size is selected the development of the fracture process zone is hindered by the boundary conditions. If on the other hand, a large specimen size is selected the crack does not form uniformly over the cross-section, causing the sample to flex sideways, in which case the load condition at fracture is no longer purely uniaxial. This poses a problem for concrete mixes containing large fibres, such as steel fibres. For these mixes relatively large tensile specimens are required to ensure a fibre distribution in the ligament area, which is representative of the dispersion found in full-size structures.

The splitting tensile test, also known as the Brazillian test, is typically performed on $150 \mathrm{~mm}$ diameter, $300 \mathrm{~mm}$ long, cylindrical specimens. These dimensions are appropriate to create representative samples for most fibre reinforced concrete mixtures. Like the direct tension test, the splitting tensile test is also known to have a number of limitations. A disadvantage of the splitting tensile test compared to the direct tension test is that it does not provide suitable data on the post crack behaviour of the material. The splitting tensile test provides a measure of tensile strength only. For normal strength concrete the tensile strength obtained using this test can be expected to be 10 to 40 percent higher than the actual uniaxial strength of the material [2]. Importantly for this paper, Olesen et al [2] have shown that in the standard configuration the test cannot be used to obtain the tensile strength of FRC due to the ductility of the material. The challenges in using the split cylinder test for both plain and fibre reinforced concrete are caused by the difference between the simple boundary conditions and linear elastic material behaviour 
assumed in the continuum mechanics model of the test and the actual boundary conditions of the test and the non-linear material response.

The objective of this paper is to present a methodology to obtain a close estimate of the true tensile strength of fibre reinforced concrete from an adjusted tensile splitting test procedure. The methodology builds on concepts previously introduced by various researchers in the field. The adjusted tensile splitting method can be summarized as follows: The linear elastic tensile stress calculation in the specimen is corrected for the influence of the width of the load strip by using the relation Tang [3] developed. The fracture mechanics size-effect, which is due to the quasi-brittle material behaviour of concrete, is reduced to acceptable proportions based on the recommendations by Rocco et al [4], [5]. The novel part of the method is that the transition from the linear elastic pre-crack behaviour to the ductile post crack behaviour of FRC is identified by monitoring transversal deformation perpendicular to the load direction during the test. The reasoning behind the different steps of the methodology is described in detail in the following section.

\section{Background}

The calculation of the maximum principal stress in the splitting tensile test is based on the two dimensional problem shown in Fig. 1a. The plane stress, solid mechanics, solution for this problem as provided by Timoshenko and Goodier [6] allows calculation of the horizontal normal stress $\left(\sigma_{x x}\right)$ along the loading axis of two equal and opposed point loads using Equation 1:

$$
\sigma_{x x}=\frac{2 P}{\pi D}
$$

Where $D$ is the specimen diameter and $P$ is the magnitude of the point loads. A point load in the plane stress problem corresponds to a load per unit length of the cylinder specimen, which is how $P$ is used throughout the paper. The load causes a uniform tensile stress state along the loading axis of the specimen. In conventional test methods it is assumed that $f_{t}$ is equal to $\sigma_{x x}$ in the peak load condition recorded during the test. The actual loading condition in the splitting 
test setup (shown in Fig. 1b) differs from the simple boundary conditions assumed in Fig. 1a. In reality the loads are introduced to the specimen by means of a loading strip with a certain width instead of point loads. The loading strip causes a non-uniform distribution of the normal stress along the loading axis of the specimen, with a compressive zone in the material near the contact area of the load strip. The size of the compressive zone depends on the size of the load strip. The deviation from the assumed simple boundary conditions leads to an overestimation of $f_{t}$ obtained from Equation 1 [5]. Tang [3] corrected the linear elastic plane stress solution for the presence of a load strip with a finite width. Based on the correction by Tang [3] the horizontal normal stress at the centre of the cylinder may be calculated using:

$$
\sigma_{x x}=\frac{2 P}{\pi D}\left[1-\left(\frac{b}{D}\right)^{2}\right]^{\frac{2}{3}}
$$

Where $b$ is the width of the load strip. This correction results in a downward adjustment of 4 percent in the maximum stress, if the size of the load strip is as specified in ASTM 496 [5]. The correction of the linear elastic load condition therefore accounts only for a small portion of the overestimation of $f_{t}$ reported for splitting tensile tests.

A larger proportion of the difference between the splitting tensile strength and the true tensile strength is due to the quasi-brittle material behaviour of concrete and the related fracture mechanics size effect. Rocco et al [4], [5] investigated the influence of the fracture mechanics size effect on the results of the tensile splitting test. Their analysis shows that differences of up to 40 percent in tensile strength can be found depending on the width of the load strip and the applied loading speed. In a later publication [7], the same authors reported a 30 percent difference in tensile strength values between much used international standards (ASTM C-469, ISO 4105, BS 1881-117). They showed that the split cylinder test can yield a true indication of the tensile strength as long as the width of the loading strip does not exceed 8 percent of the diameter of the specimen and the speed of loading does not exceed 1.0 MPa per minute [4]. 
As mentioned above, conventional test methods use the Timoshenko and Goodier [6] equation to calculate the tensile strength of the material. The assumed fracture mode is therefore rupture starting at the centre of the specimen. The crack would grow in the direction of the highest stress, i.e. towards the loading strips. In a study on mechanisms of rupture in the splitting test, Rocco et al [8] reported that this primary mode of failure, schematically shown in Fig. 2a, is followed by secondary cracking, as shown in Fig. 2b. This implies that after the tensile strength of the material is reached and a crack has formed in the centre of the specimen along the loading axis, the stresses redistribute and new highly stressed areas are created. By measuring the transversal deformation during the test, Rocco et al [8] found that both the principal crack formation and secondary crack formation have a peak as shown in Fig. 2c. The relative magnitude of the peaks varies depending on material type and specimen geometry. Note that in conventional test methods $f_{t}$ is calculated from the maximum load condition recorded in the test. In a situation where the secondary peak load exceeds the principal peak load, the linear elastic solutions offered by both Equations 1 and 2 would be invalid.

\section{Experimental setup}

Based on the theory discussed in the previous section an adjusted tensile splitting tensile test procedure was developed. The test configurations used for the study are shown in Fig. 3. Two different methods were used to record the transversal deformation of the specimens during the tests. Initially spring loaded Linear Variable Displacement Transducers (LVDTs) were held by fixtures mounted to the base plate in the test machine as shown in Fig. 3a. The LVDTs were positioned at centre line of the specimen and at the centre of its length. The method proved successful, but was later replaced by the more robust measuring system schematically in Fig. 3b. In this setup the transversal deformation was measured using LVDTs mounted to datum points which were glued to the specimens. Measurements were taken on both sides of the cylinder. Photos of both test configurations are shown in Fig. 4. In accordance with the recommendations for reduction of size effect by Rocco et al [4], a loading strip of $12 \mathrm{~mm}$ width 
( $8 \%$ of the $150 \mathrm{~mm}$ diameter) was used and the loading rate was controlled at 1 MPa per minute.

The adjusted tensile splitting tests were performed on high performance fibre reinforced concrete mixes. The mix designs are typical for materials used in an innovative ultra-thin concrete road pavement system. The designs have a maximum aggregate size of $6.7 \mathrm{~mm}$. The mix compositions by weight are shown in Table 1. The mixes were cast as part of a research project spanning a number of years. The high performance concrete contains steel fibres to impede macro cracking as well synthetic fibres to retard micro cracking.

The engineering properties for the mix at an age of 28 days, required for numerical simulation of the cylinder splitting tests are shown in Table 2 . The compressive strength $\left(f_{c}\right)$ of the different mixes, which is shown here for comparison purposes only, was determined in accordance with British Standard BS-1881 [9]. The ASTM C469 [10] standard method was used to obtain an estimate of the static modulus of elasticity $(E)$ and Poisson's ratio $(v)$. The specific fracture energy $\left(G_{f}\right)$ was determined from three point bending tests as published elsewhere [11], [12]. From this work the material is known to exhibit strain softening behaviour in opening mode fracture.

\section{Results}

The load-transversal deformation curves obtained for the cylinder splitting tests performed as part of this study are shown in Fig. 5. The tests on Mixes A, B and C were performed using the LVDT setup shown in Fig. 3a, while the improved test setup shown in Fig. 3b was used for the tests on Mix D. The observed material behaviour shows two peak load condition, which is comparable to the graph shown in Fig. 2c. The results indicate that the material behaves linear elastically until a first peak is reached at load level $\left(P_{I}\right)$. The load stabilizes at this level before increasing again with an increase deformation. Eventually a second and higher peak load $\left(P_{u}\right)$ is reached. In conventional splitting tests, this second, ultimate peak load is the only value that would be recorded. Using the approach in 
conventional test methods, the nominal ultimate tensile stress $\sigma_{N u}$ is calculated using the relation in Equation 1:

$$
\sigma_{N u}=\frac{2 P_{u}}{\pi D}
$$

The results of this study however, indicate that $P_{u}$ is related to a secondary cracking mechanism in the tests and not to linear elastic tensile stress distribution in the cylinder.

It is proposed that a close estimate of the true tensile strength $\left(f_{t}\right)$ may be obtained from the linear elastic limit state at load level $P_{I}$, while also taking into account the correction for the width of the load strip proposed by Tang [3]:

$$
f_{t}=\frac{2 P_{I}}{\pi D}\left[1-\left(\frac{b}{D}\right)^{2}\right]^{\frac{2}{3}}
$$

The values obtained for $\sigma_{N u}$ and $f_{t}$ after correction for statistical outliers are shown in Table 3. The values for $\sigma_{N u}$ are up to 45 percent higher than the values for $f_{t}$. The correction proposed by Tang [3] accounts for only 4 percent of this difference.

The measurement of transversal deformation using LVDTs has a limited precision, especially when the fixtures are mounted to the base plate as was done for the first mixes. The objective however is to identify the point at which the linear elastic stress distribution ceases to exist, for which purpose the method was found to be adequate.

\section{Numerical simulation}

To further analyse the stress condition in the experiments, numerical modelling of tests was performed using the commercial software framework Abaqus. The post crack stress softening behaviour of the material is simulated using the cohesive crack approach first introduced for concrete by Hillerborg et al [13]. In cohesive crack models, the material behaves linear elastically until the principle stress reaches the tensile strength of the material and a crack is formed. After the introduction of the crack in the material, stresses are still transferred over the 
cracked surface. In FRC this is due to the combined bridging action of fibres and aggregate interlock. Stress transfer over the crack is described by a softening function. The crack bridging tensile stress $(\sigma)$ is written as a function of the crack width $(w)$ :

$$
\sigma=\mathrm{f}(w)
$$

Research on concrete with similar steel fibres from the same producer as used in this study has shown that when a crack forms the magnitude of stress transferred across the crack drops rapidly until it stabilizes at a lower stress before decreasing further at a slower pace [14]. The initial rapid decrease in tensile capacity is due to brittle failure of cement bonds. As the crack opening increases the fibres are activated, which results in a more gradual stress reduction while the fibres are slowly pulled out of the matrix. This material behaviour can be modelled suitably using a softening function with crack tip singularity [12]. The shape of the softening function is shown in Fig. 6. The softening relation consists of a linear and an exponential part. When the tensile strength $\left(f_{t}\right)$ of the material is reached a crack is formed and the stress transferred across the crack reduces linearly with an increase in $w$ for $0<w<w_{1}$ according to:

$$
\sigma=f_{t}\left(\frac{f_{t}-\sigma_{1}}{w_{1}}\right) w
$$

Once $w_{1}$ is reached softening becomes exponential over domain $w_{1}<w<\infty$. The exponential softening is defined by the value of $\sigma_{l}$ and the remaining fracture energy $G_{f, l}$. This is the specific fracture energy $G_{f}$ less the energy dissipated under the linear softening:

$$
G_{f, 1}=G_{f}-\left(\frac{f_{t}+\sigma_{1}}{2}\right) w_{1}
$$

The values for $\sigma_{l}$ were obtained from calibration in numerical simulation of three point bending tests [12]. The exponential part of the softening function is given by:

$$
\sigma_{w}=\sigma_{1} E X P\left(-\frac{\sigma_{1}}{G_{f, 1}}\left(w-w_{1}\right)\right)
$$


The optimized softening functions for the mixes under study are shown in Fig. 7. The softening curve parameters are also shown in the figure. The tensile strength $f_{t}$ is as shown in Table 3, and the fracture energy is as given for the different mixes in Table 2. A value of $0.005 \mathrm{~mm}$ was used for $w_{1}$ to facilitate the crack tip singularity.

Owing to symmetry, only a quarter of the cylinder test needs to be modelled. The geometry of the numerical model is shown in Fig. 8. A vertical zone of $1 \mathrm{~mm}$ x $1 \mathrm{~mm}$ sized, standard ABAQUS plane stress cohesive elements was provided along the loading axis. The cohesive elements behave linear elastically based on the values for $E$ and $v$ from Table 2 until the tensile strength is reached, after which damage evolves as defined by softening curves in Fig 7. The behaviour of the remainder of the concrete section is simulated using plain stress linear elastic bulk elements, with the values of $E$ and $v$ from Table 2. To accurately simulate the load introduction to the specimen, the steel loading strip including the ply wood interface strip is also modelled, assuming $E=210 \mathrm{GPa}$ and $v=0.25$ for the steel and $E=5 \mathrm{GPa}$ and $v=0.3$ for the wood.

Fig 9 shows the simulated load- transversal deformation response for the different mixes. The simulation is successful in predicting the first peak load $P_{I}$ at which a crack is introduced. If the obtained $P_{I}$ values are used to back-calculate $f_{t}$ using Equation 4 the results are within 1 percent of the input value. This confirms the need to use the correction for boundary conditions proposed by Tang (1994), on which Equation 4 is based. Importantly, the material response in the numerical simulation is similar to the observed behaviour in the experiments. After reaching the first peak, the load level stabilizes and then starts to increase again. The numerical analysis allows a study of the stress distribution at the different stages of the test. Fig. 10a shows the principal stress distribution just before a crack forms at the centre of the specimen. Highly stressed areas are indicated in the figure with "A". The stress condition in Fig. 10a represents the linear elastic stress distribution assumed in the calculation of the tensile strength using Equations 1 and 2. Once the tensile strength of the material is reached, a crack forms at the centre of the specimen and propagates upward as shown in Fig 10b. The resulting stress redistribution sees the relaxation of stresses along the loading axis and, at 
the same time, the formation of highly stressed areas at the top and the side of the specimen as shown in Fig 10c. The stresses in these areas exceed the tensile strength of the material and would lead to secondary cracking similar to the observations by Rocco et al [8]. The model does not contain cohesive elements in these regions and therefore no secondary cracking occurs in the simulations. Consequently, the load- transversal deformation curves in Fig. 9 do not show a secondary peak, but instead keep increasing. The exact magnitude of the secondary peak is however, of little importance to the discussion in this paper. The main outcome of the numerical simulation is that the fracture mechanics modelling confirms the occurrence of an initial linear elastic peak load $P_{I}$ and that after reaching this peak load stresses redistribute, eventually leading to a second and high peak load $P_{u}$ at which secondary cracking will occur.

\section{Conclusions}

The objective of this paper is to present a methodology to obtain a close estimate of the true tensile strength $\left(f_{t}\right)$ of Fibre Reinforced Concrete (FRC) from an adjusted tensile splitting test procedure. The results show that $f_{t}$ of FRC may be determined from cylinder splitting tests provided that: measures to reduce size effect are observed, the calculation is corrected for the influence of width of the loading strip, and the transversal deformation is measured.

Without the measurement of the transversal deformation, the ductile post crack behaviour of the material will obscure the tensile splitting strength. If only the ultimate peak load $\left(P_{u}\right)$ is recorded, as prescribed by conventional test methods, a tensile strength is calculated that is not related to a linear elastic tensile load condition in the sample. The numerical simulation confirms that the ultimate peak load is related to secondary cracking mechanisms. The first peak $P_{I}$ represents the linear elastic limit state and from it a best estimate of the tensile strength material property can be calculated.

The tensile splitting methodology for fibre reinforced concrete developed in this paper provides a relatively simple alternative to the more complex direct tensile testing approach. Direct tensile testing yields more detail on the post cracking 
behaviour of the composite material. However, if only a measure of the tensile strength is required, for instance as an input to fracture mechanics models, the presented tensile splitting methodology will suffice.

The mixes under study in this paper exhibit strain softening behaviour in fracture. It is not known whether the proposed methodology is sensitive enough to be able to identify the elastic limit state for strain hardening composites. The application of the methodology to such materials requires further research.

\section{References}

1. Bažant ZP (2002) Concrete fracture models: testing and practice. Engineering Fracture Mechanics. 69: 165-205.

2. Olesen JF, Østergaard L, Stang H (2006) Nonlinear fracture mechanics and plasticity of the split cylinder test. Materials and Structures 39: 421-432.

3. Tang T (1994) Effects of load-distributed width on split tension of unnotched and notched cylindrical specimens. Journal of Testing and Evaluation 22: 401-409.

4. Rocco C, Guinea G, Planas J, Elices M (1999) Size effect and boundary conditions in the Brazilian test: Experimental verification. Materials and Structures 32: 210-217.

5. Rocco C, Guinea G, Planas J, Elices M (1999) Size effect and boundary conditions in the Brazilian test: Theoretical analysis. Materials and Structures. 32: 437-444.

6. Timoshenko SP, Goodier JN (1970) Theory of Elasticity. 3rd edition, McGraw-Hill Book Company.

7. Rocco C, Guinea G, Planas J, Elices M (2001) Review of the splitting-test standards from a fracture mechanics point of view. Cement and Concrete Research 31: 73-82.

8. Rocco C, Guinea G, Planas J, Elices M (1999) Mechanisms of rupture in splitting tests. ACI Materials Journal 96: 52-60.

9. BSI (1983) BS 1881: Testing concrete. Part 116: 1983 Method for determination of compressive strength of concrete cubes. British Standard Institute

10. ASTM (2008) ASTM C469-02 Standard Test Method for Static Modulus of Elasticity and Poisson's Ratio of Concrete in Compression. Annual Book of ASTM Standards 2008: Section 04.02.

11. Denneman E, Kearsley EP, Visser AT (2010) Size-effect in high performance concrete road pavement materials. Van Zijl GPAG, Boshoff WP (Eds.) Advances in cement-based materials. CRC Press, London, pp 53-58.

12. Denneman E, Wu R, Kearsley EP, Visser AT (n.d.) Discrete fracture in high performance fibre reinforced concrete materials. Article under $2^{\text {nd }}$ review. 
13. Hillerborg A, Modéer M, Petersson P (1976) Analysis of crack formation and crack growth in concrete by means of fracture mechanics and finite elements. Cement And Concrete. Research 6: 773-782

14. Lim T, Paramasivam P, Lee S (1987) Analytical model for tensile behavior of steel-fiber concrete. ACI Materials Journal 84: 286-298. 

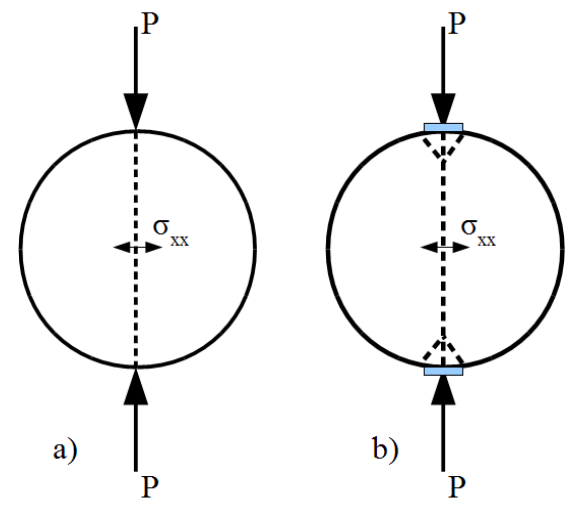

Fig. 1: Tensile splitting test: a) Assumed load condition, b) Actual load condition
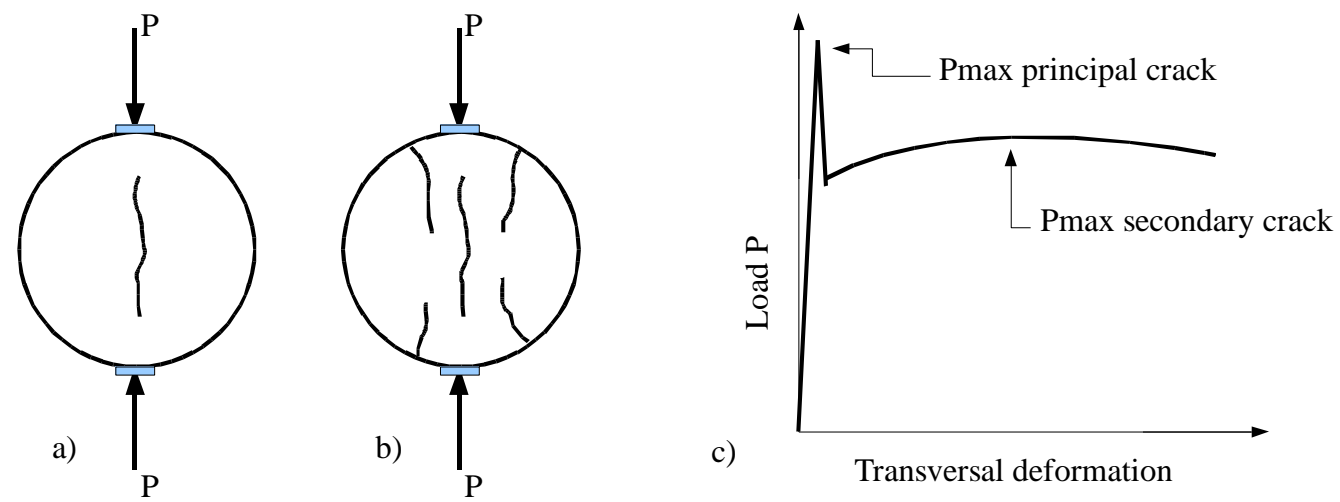

Fig. 2: a) Principal crack formation, b) Secondary crack formation, c) schematic load-deformation curve (after Rocco et al [8]).
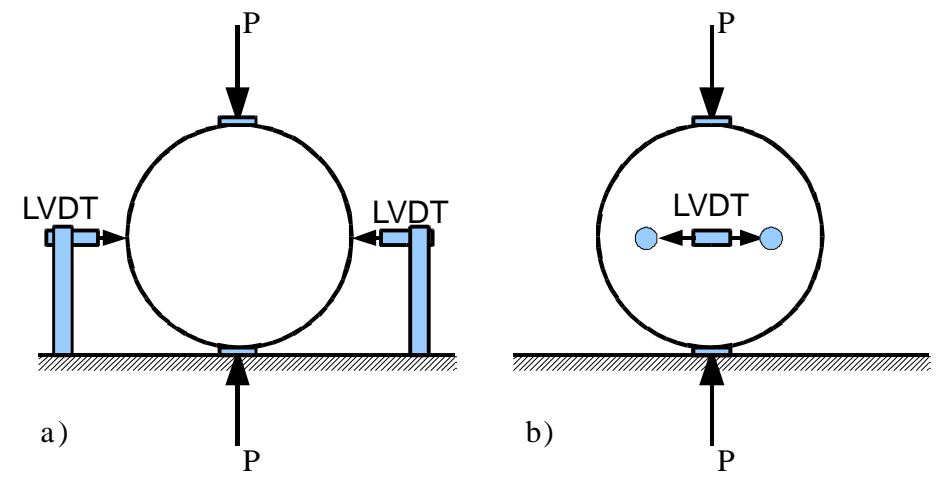

Fig. 3: a) Initial test configuration, b) Improved test setup 


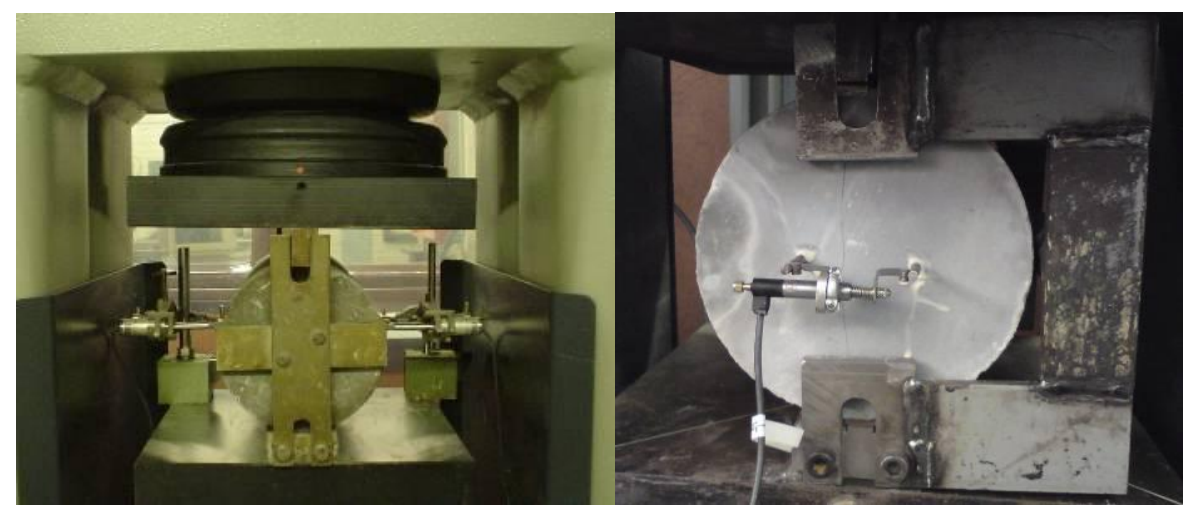

Fig. 4: Photos of the test setup

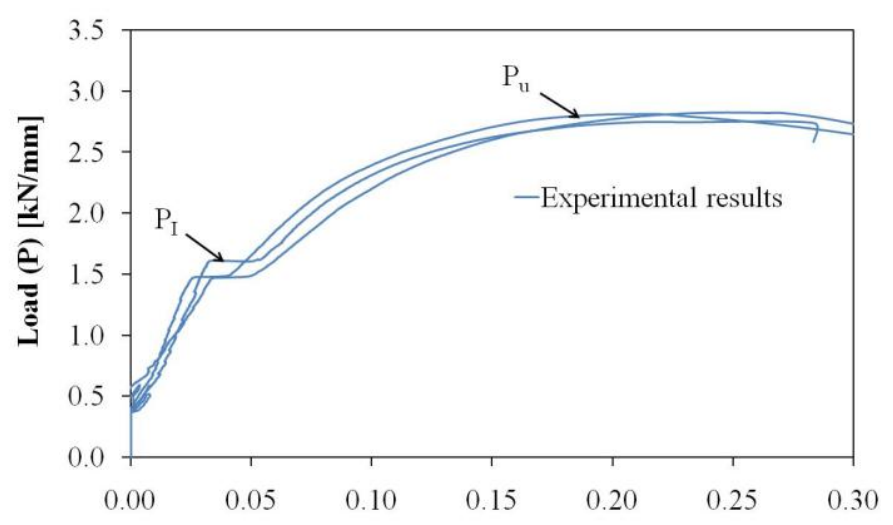

a)

Transversal deformation [mm]
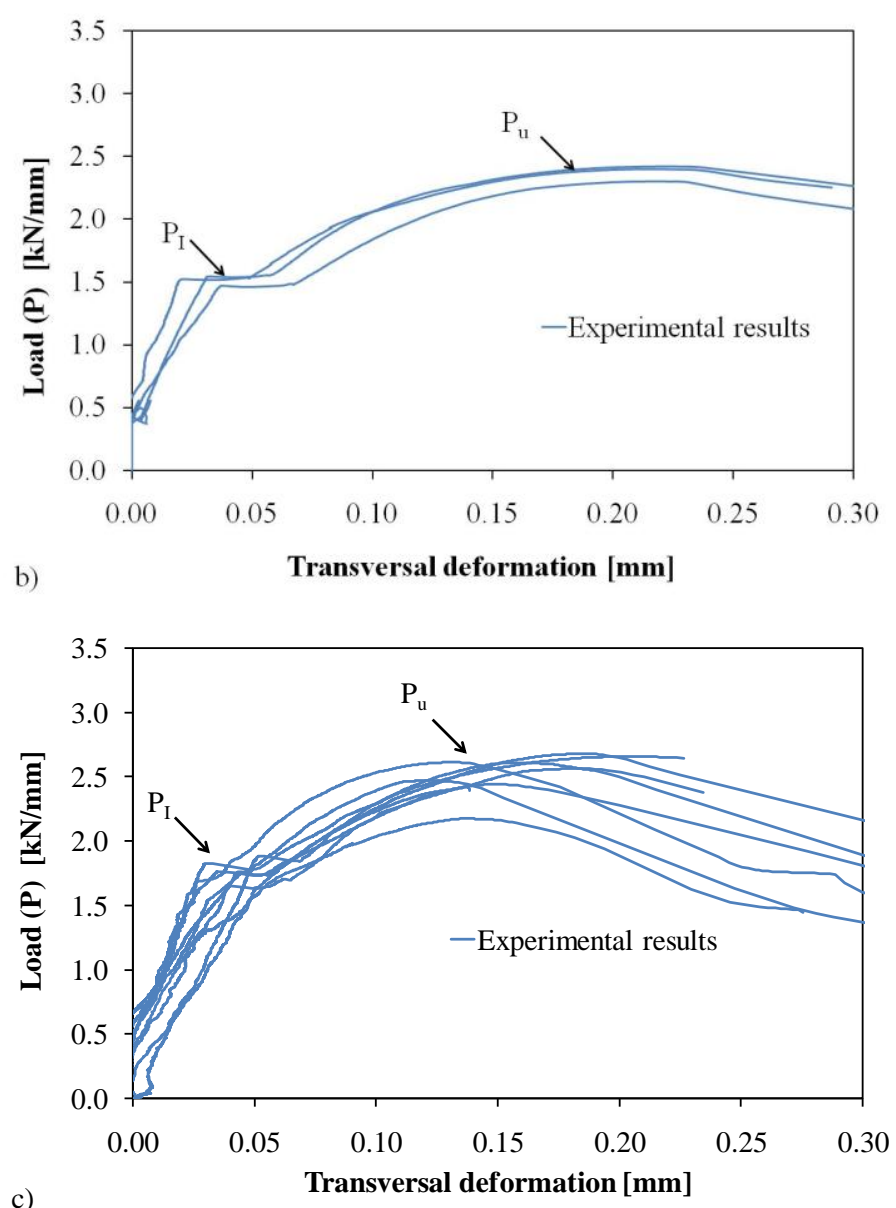


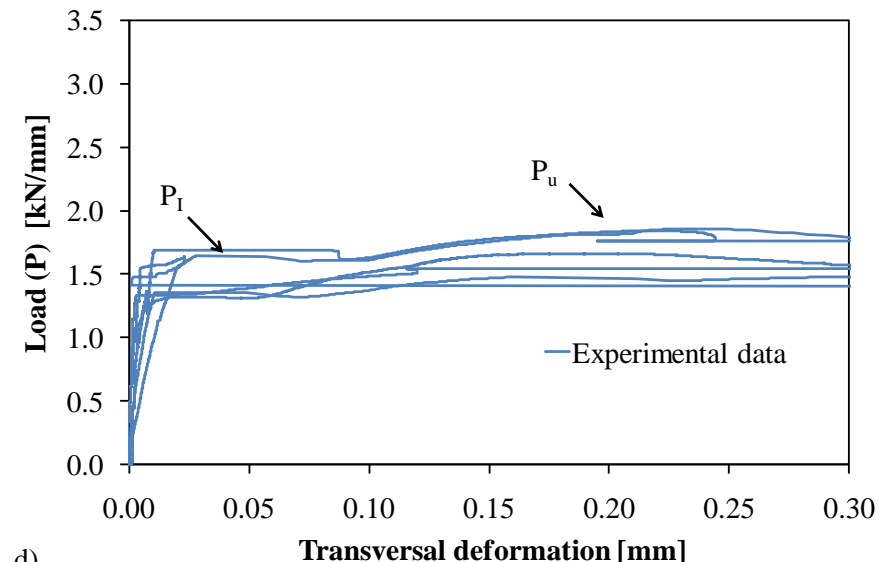

d)

Fig. 5: Load-transversal deformation curves for cylinder splitting tests on: a) Mix A specimens, b) Mix B specimens, c) Mix C specimens and d) Mix D specimens.

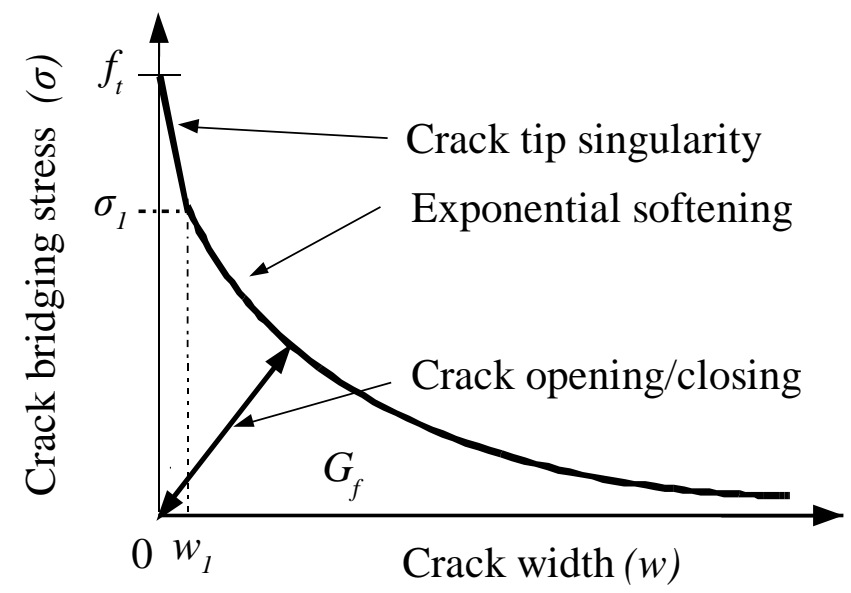

Fig. 6: Cohesive softening relation for FRC.

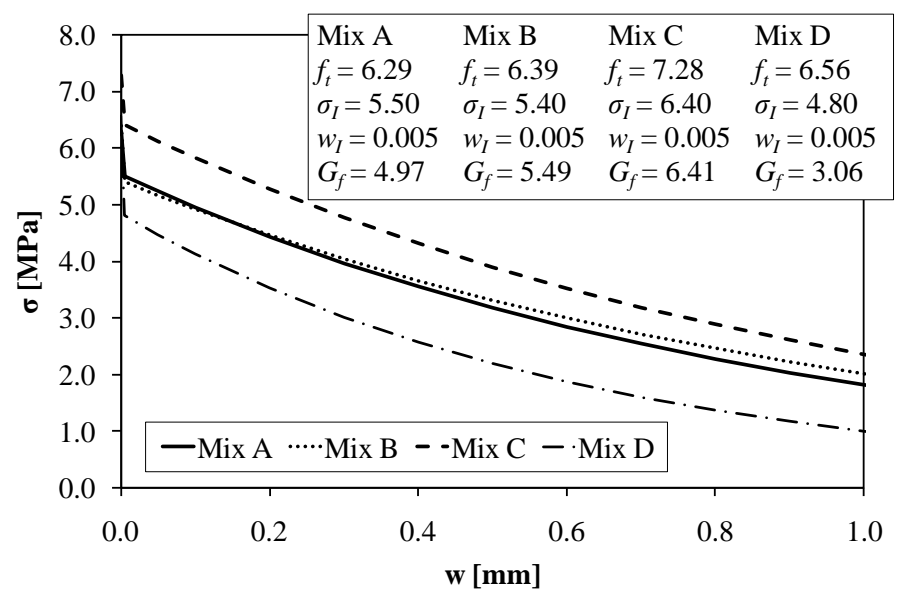

Fig. 7: Softening curves for mixes under study 


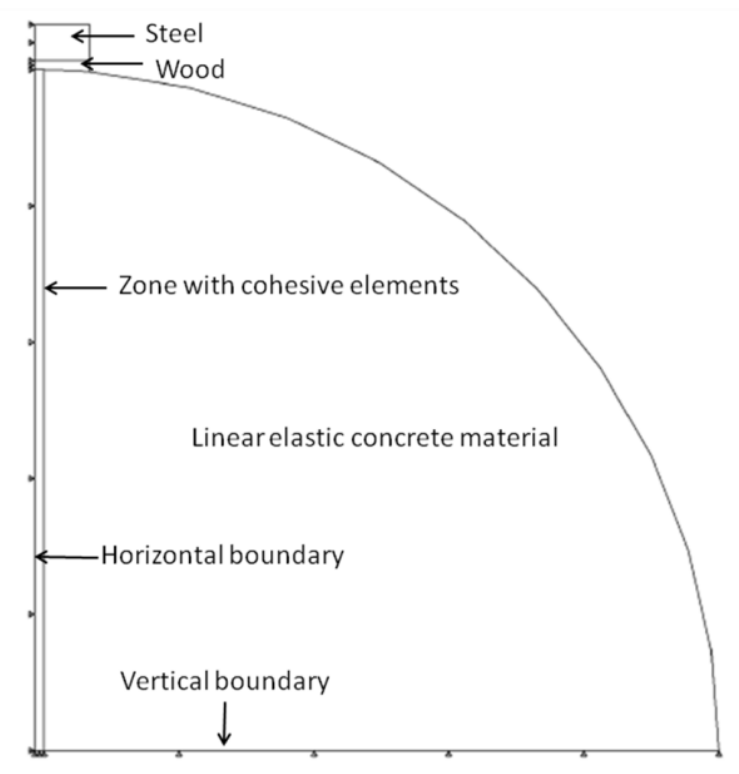

Fig. 8: Geometry of numerical model.

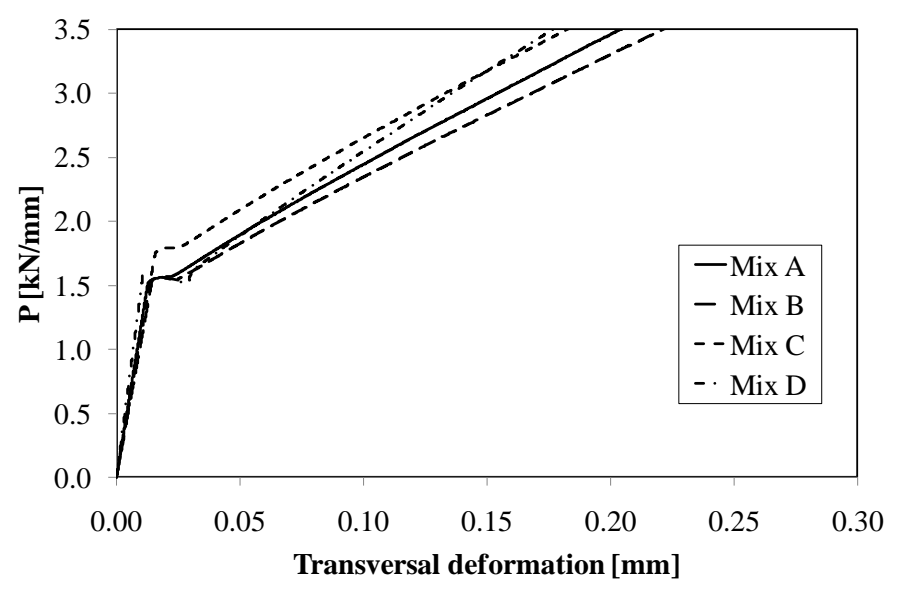

Fig. 9: Simulated load-transversal deformation response.
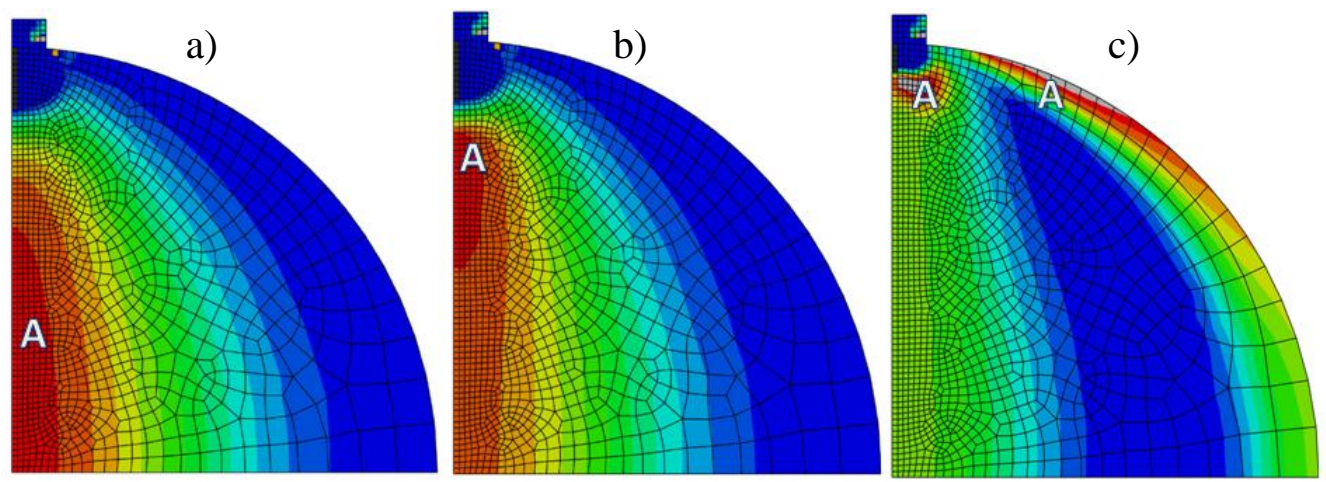

Fig. 10: Principal stress distribution in numerical model. 
Table 1. Mix proportions

\begin{tabular}{|l|l|c|c|c|c|}
\hline Component & Type & $\begin{array}{c}\text { Mix A } \\
\mathbf{k g} / \mathbf{m}^{\mathbf{3}}\end{array}$ & $\begin{array}{c}\text { Mix B } \\
\mathbf{k g} / \mathbf{m}^{\mathbf{3}}\end{array}$ & $\begin{array}{c}\text { Mix C } \\
\mathbf{k g} / \mathbf{m}^{\mathbf{3}}\end{array}$ & $\begin{array}{c}\text { Mix D } \\
\mathbf{k g} / \mathbf{m}^{\mathbf{3}}\end{array}$ \\
\hline Cement & $52.5 \mathrm{~N}$ & 450.3 & 448.0 & 464.5 & 450.0 \\
\hline Coarse aggregate & $6.7 \mathrm{~mm}^{\mathrm{a}}$ & 930.6 & 925.9 & 865.9 & 950.0 \\
\hline Water & Tap water & 170.7 & 169.8 & 176.1 & 165.0 \\
\hline Fine aggregate & $4.75 \mathrm{~mm}^{\mathrm{a}}$ & 725.5 & 721.8 & 750.5 & 900.0 \\
\hline Steel fibre & $30 \mathrm{~mm}^{2} .5 \mathrm{~mm}(\mathrm{lxd})$ & 80.1 & 119.5 & 120.2 & 80.0 \\
\hline Synthetic fibre & Polypropylene $12 \mathrm{~mm}$ & 2.0 & 2.0 & 2.0 & 2.0 \\
\hline Admixture & O100 \& P100 & 6.5 & 6.5 & 7.4 & 8.0 \\
\hline Silica fume & Witbank & 65.0 & 64.7 & 63.8 & 50.0 \\
\hline Fly ash & Lethabo & 80.1 & 79.6 & 78.5 & - \\
\hline
\end{tabular}

${ }^{a}$ Ferro Quartzite aggregate was used for mix A,B,C, Dolerite aggregate was used for $\operatorname{mix} \mathrm{D}$

Table 2. Engineering properties

\begin{tabular}{|c|c|c|c|c|c|c|c|c|}
\hline Mix & $\begin{array}{l}f_{c} \\
{[\mathrm{MPa}]}\end{array}$ & $\begin{array}{l}\text { Std.dev. } \\
{[\mathrm{MPa}]}\end{array}$ & $\begin{array}{l}\boldsymbol{E} \\
{[\mathrm{GPa}]}\end{array}$ & $\begin{array}{l}\text { Std.dev. } \\
{[\mathbf{G P a}]}\end{array}$ & $v$ & Std.dev. & $\begin{array}{l}\boldsymbol{G}_{\boldsymbol{f}} \\
{[\mathbf{N} / \mathbf{m m}]}\end{array}$ & $\begin{array}{l}\text { Std.dev. } \\
{[\mathbf{N} / \mathbf{m m}]}\end{array}$ \\
\hline $\mathrm{A}$ & 108.9 & 7.4 & 49.6 & 0.5 & 0.14 & 0.023 & 4.97 & 0.91 \\
\hline $\mathrm{B}$ & 115.5 & 4.9 & 46.3 & 0.3 & 0.16 & 0.012 & 5.49 & 0.96 \\
\hline C & 125.5 & 4.7 & 49.7 & 0.7 & 0.17 & 0.005 & 6.41 & 0.58 \\
\hline D & 137.2 & 6.0 & 62.9 & 0.7 & 0.15 & 0.005 & 3.53 & 0.50 \\
\hline
\end{tabular}

Table 3. Tensile strength results

\begin{tabular}{|c|c|c|c|c|c|}
\hline Mix & $\begin{array}{l}\text { Number } \\
\text { of tests }\end{array}$ & $\begin{array}{l}\sigma_{N u} \\
{[\mathrm{MPa}]}\end{array}$ & $\begin{array}{l}\text { Std.dev. } \\
{[\mathrm{MPa}]}\end{array}$ & $\begin{array}{l}f_{\boldsymbol{t}} \\
{[\mathrm{MPa}]}\end{array}$ & $\begin{array}{l}\text { Std.dev. } \\
{[\mathrm{MPa}]}\end{array}$ \\
\hline A & 3 & 10.01 & 0.27 & 6.29 & 0.25 \\
\hline B & 3 & 11.78 & 0.18 & 6.39 & 0.33 \\
\hline C & 9 & $10.86^{\mathrm{a}}$ & 0.42 & $7.28^{\mathrm{a}}$ & 0.51 \\
\hline D & 6 & 7.21 & 0.60 & 6.56 & 0.73 \\
\hline
\end{tabular}

${ }^{\mathrm{a}}$ Outlier omitted 

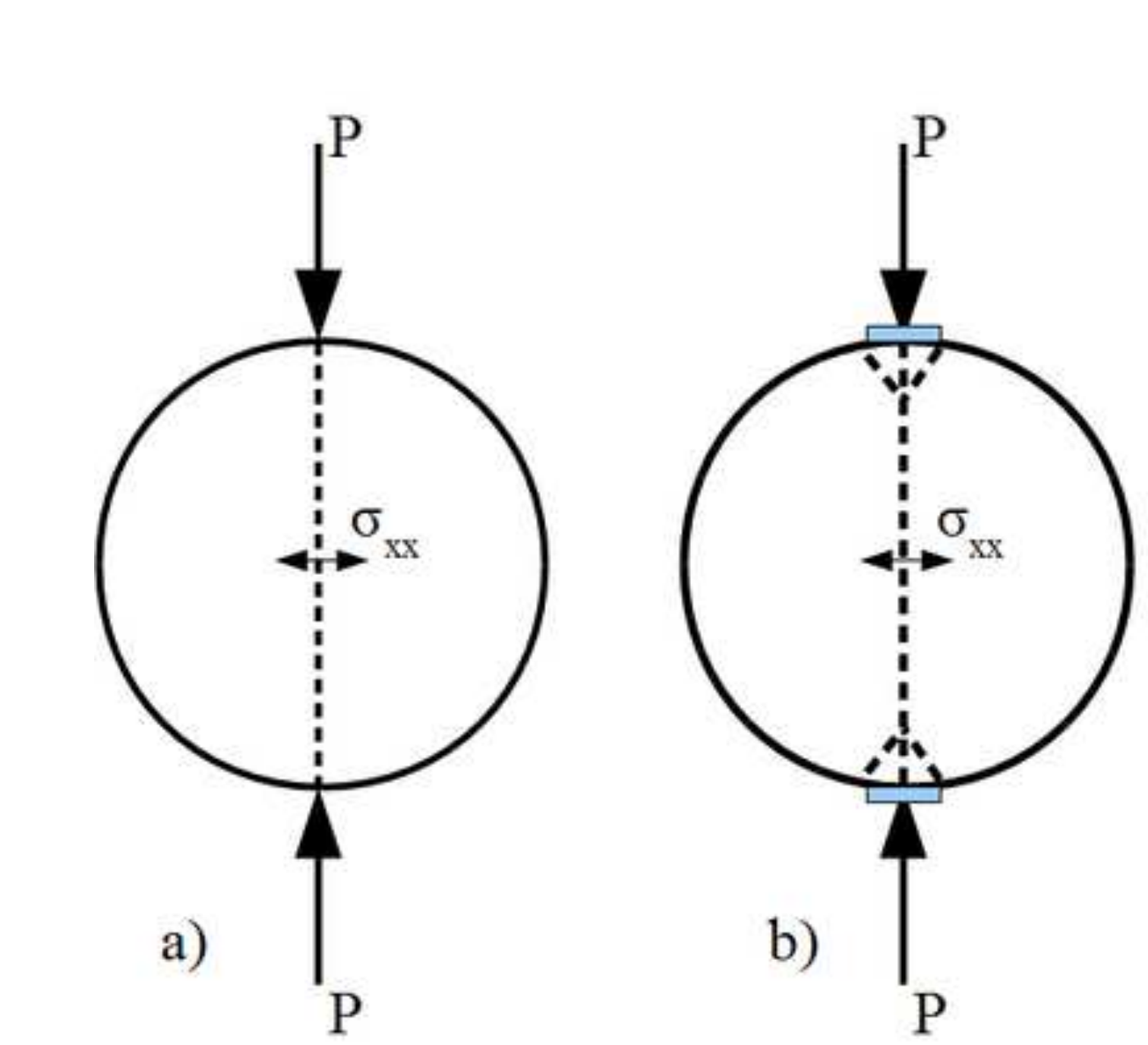

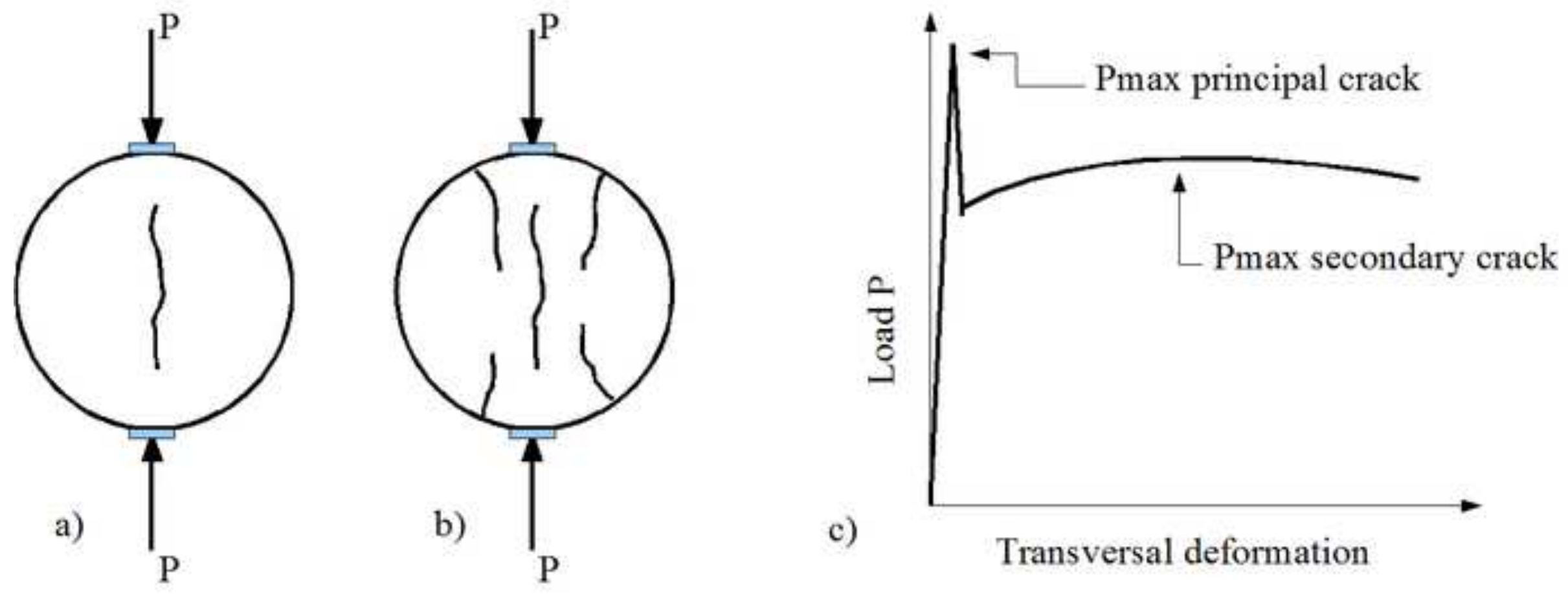

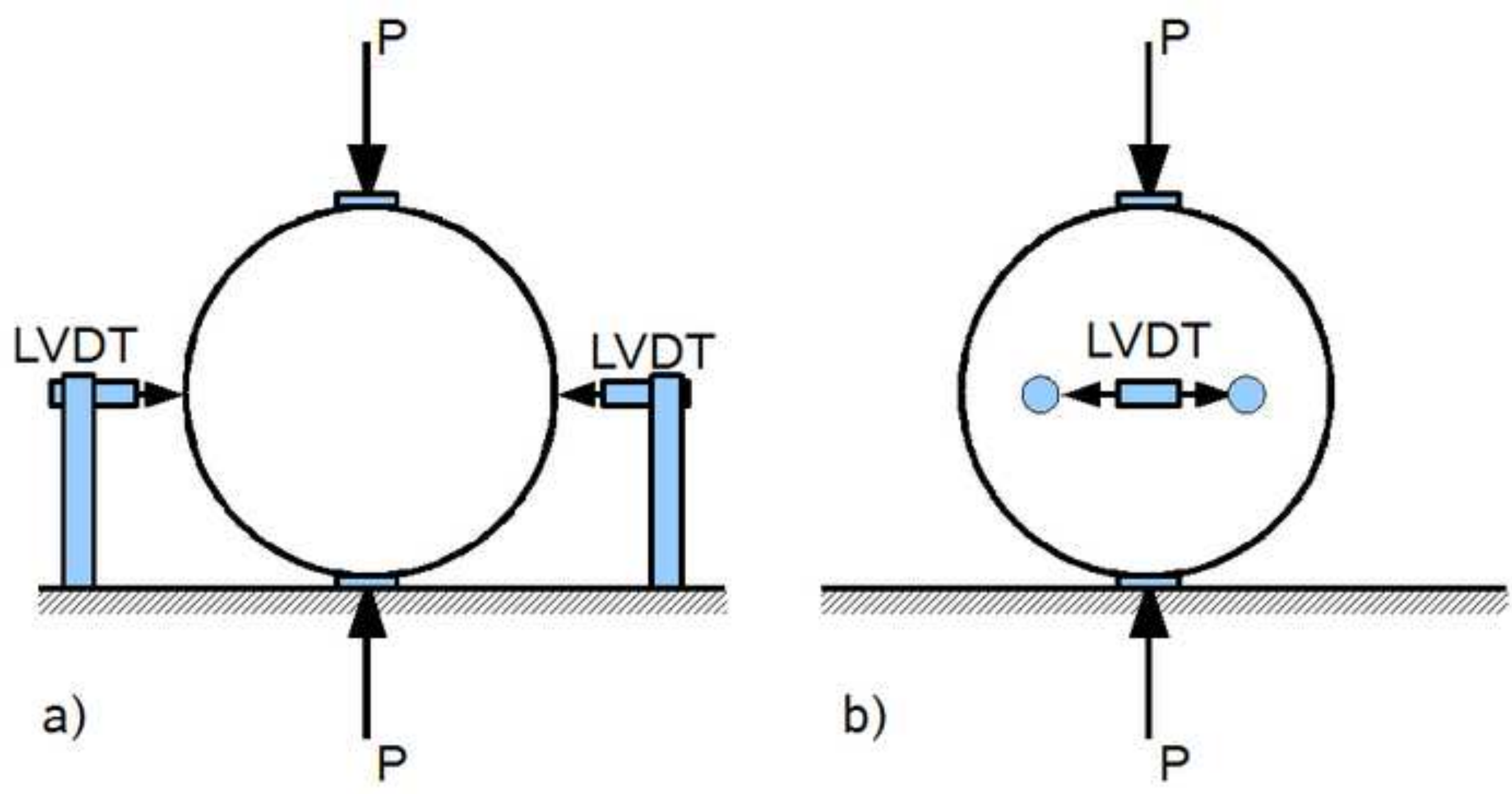
Fig 4
Click here to download high resolution image
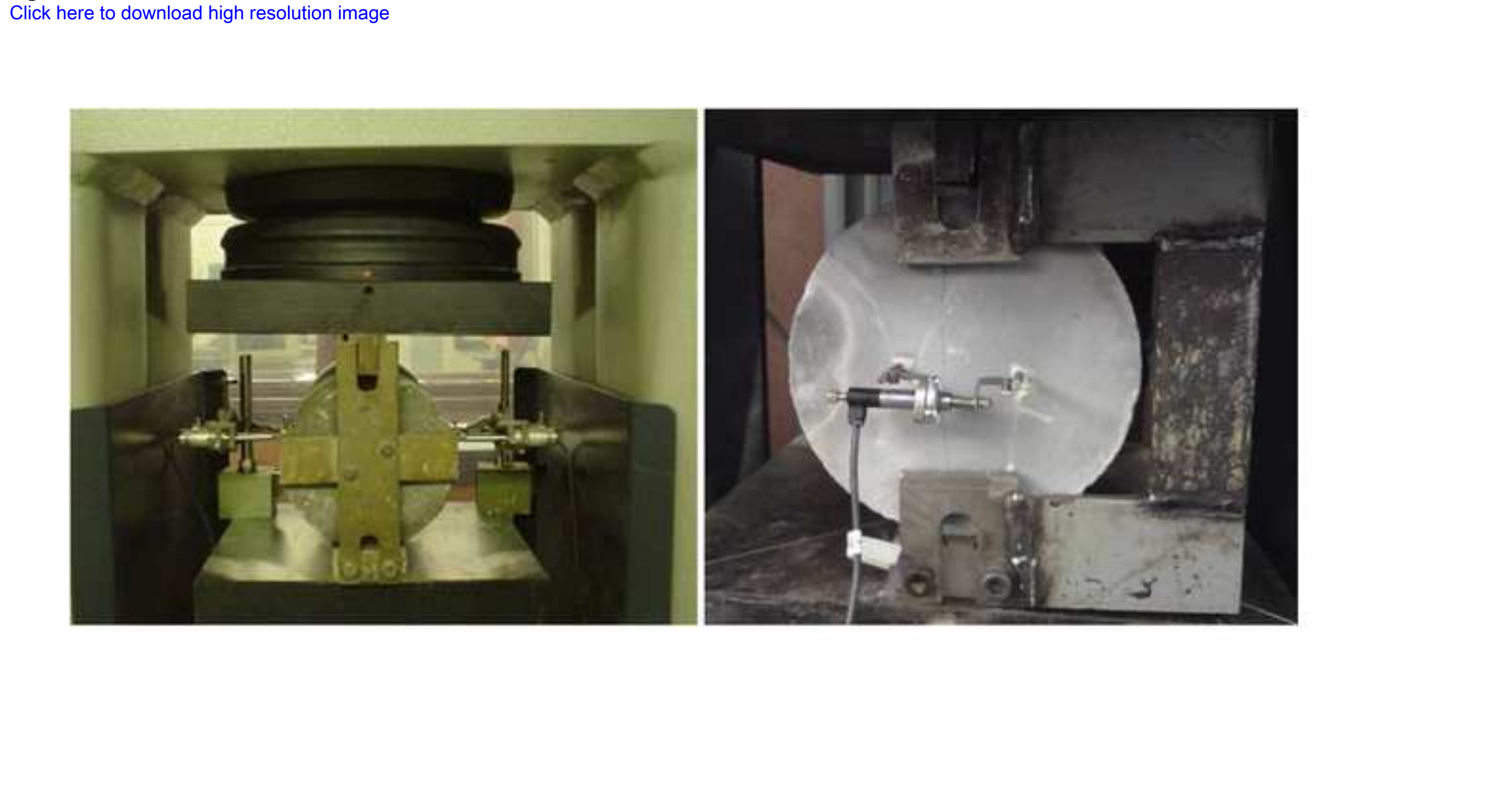


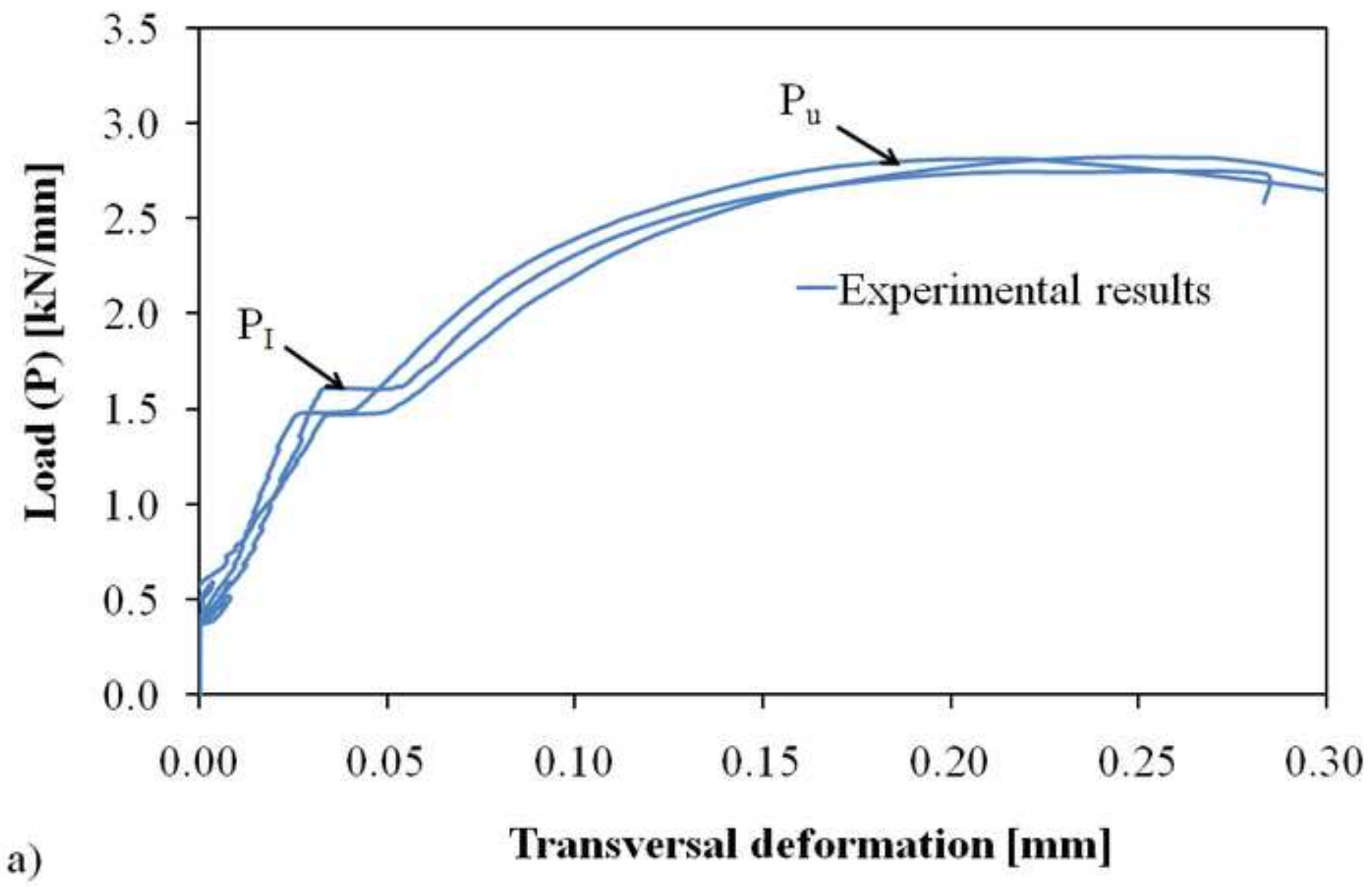




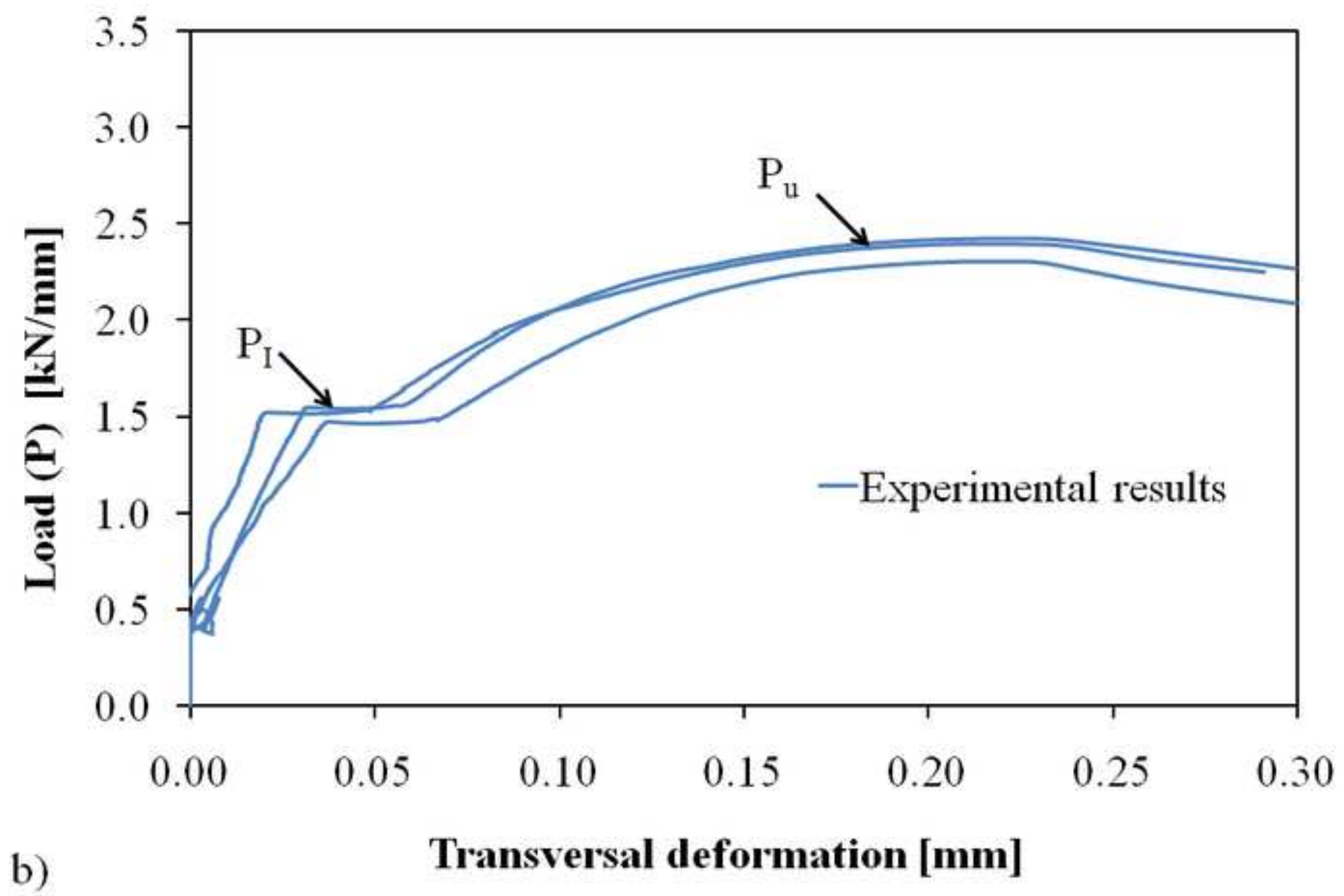




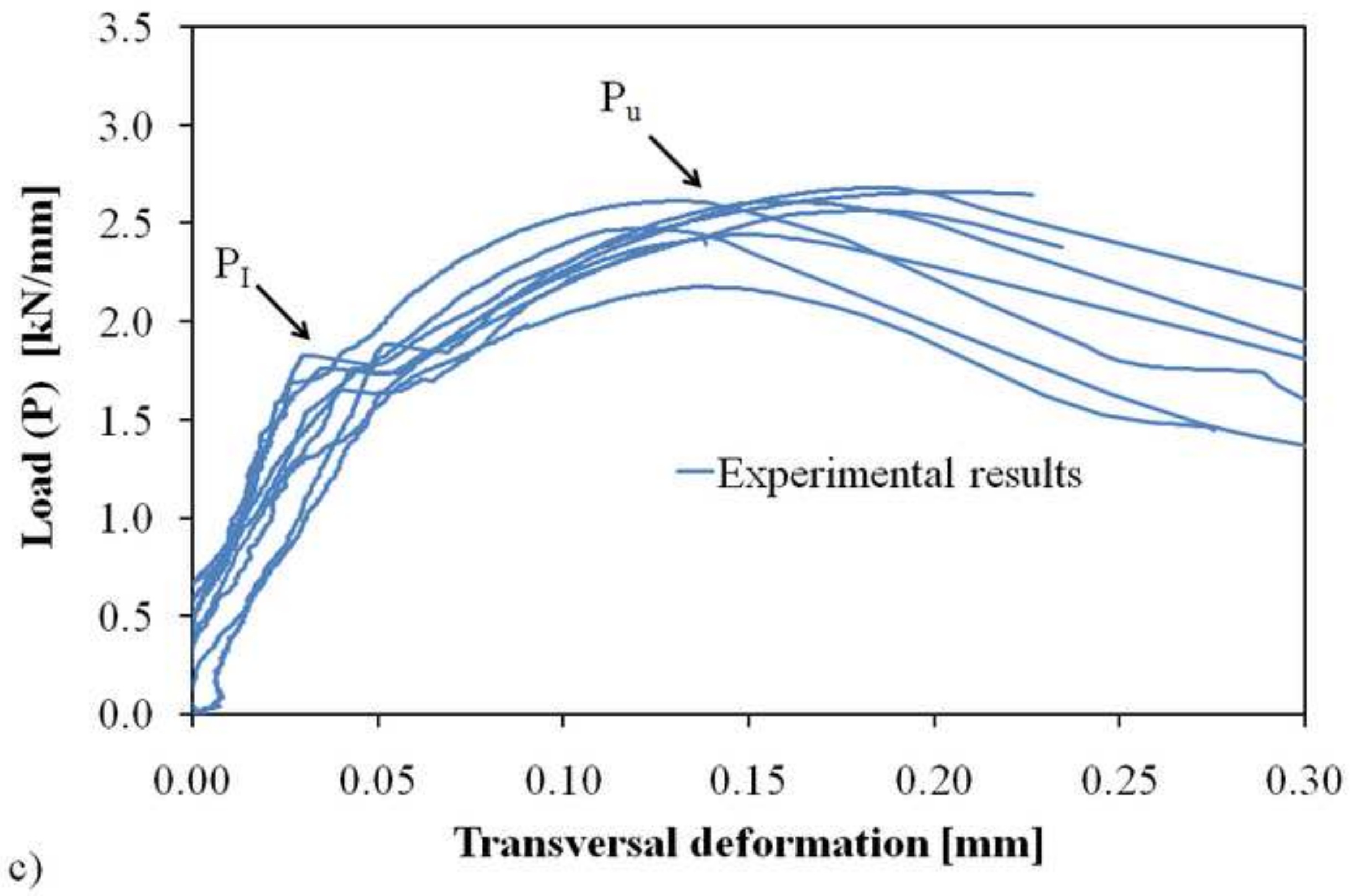




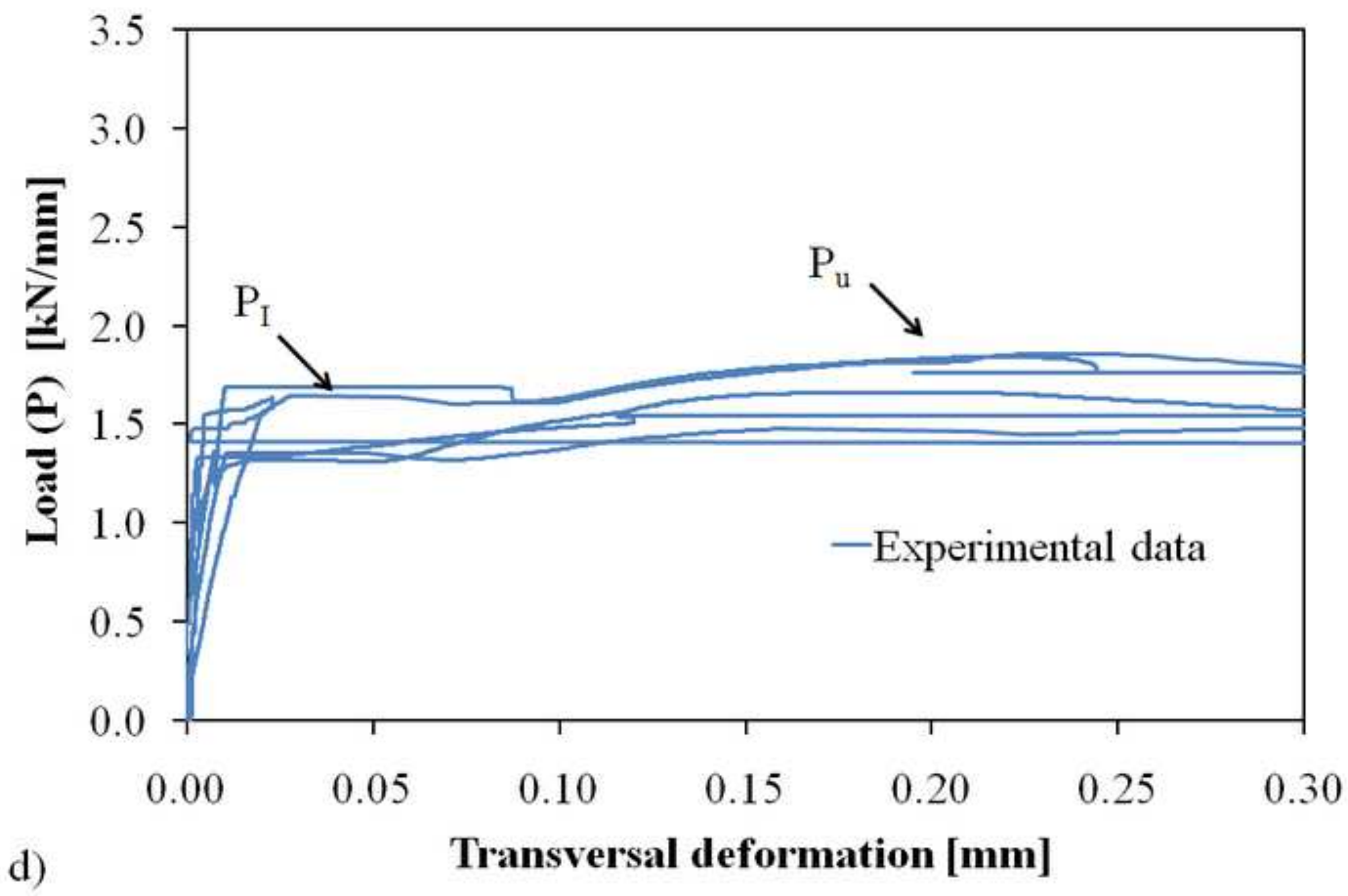




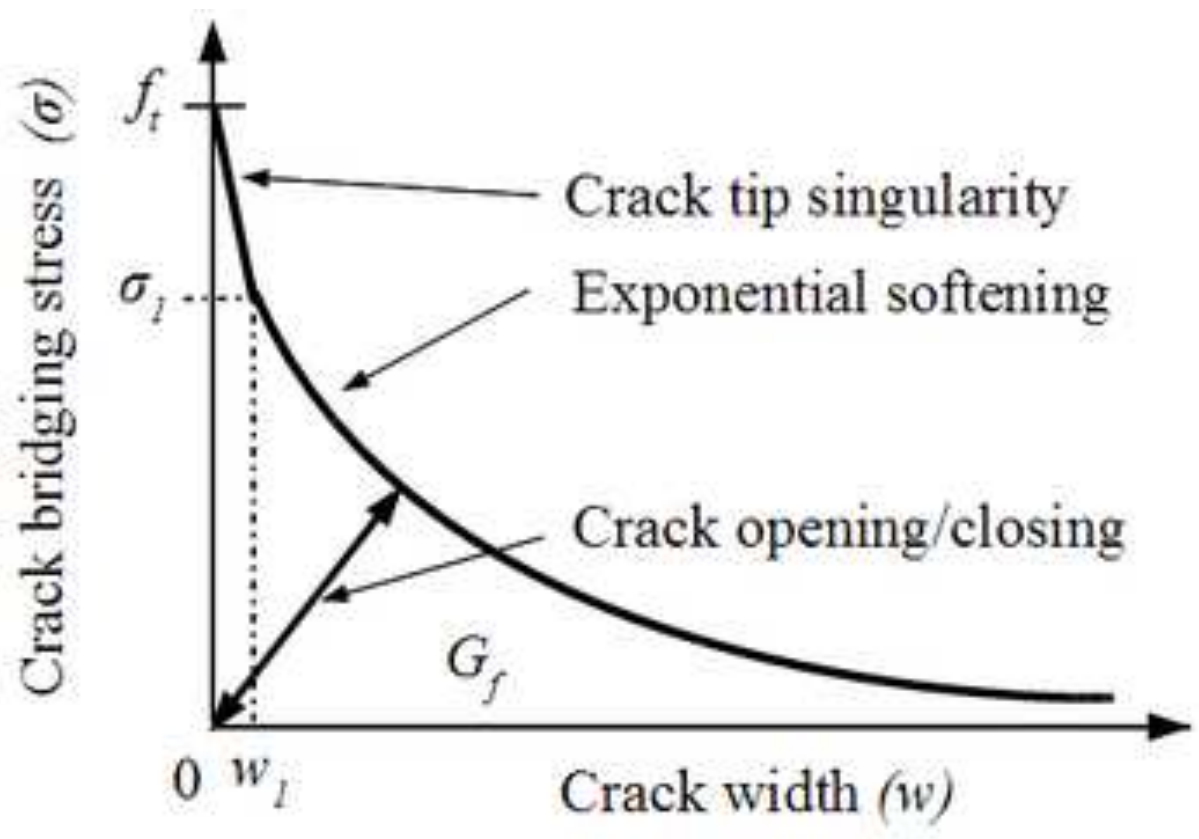




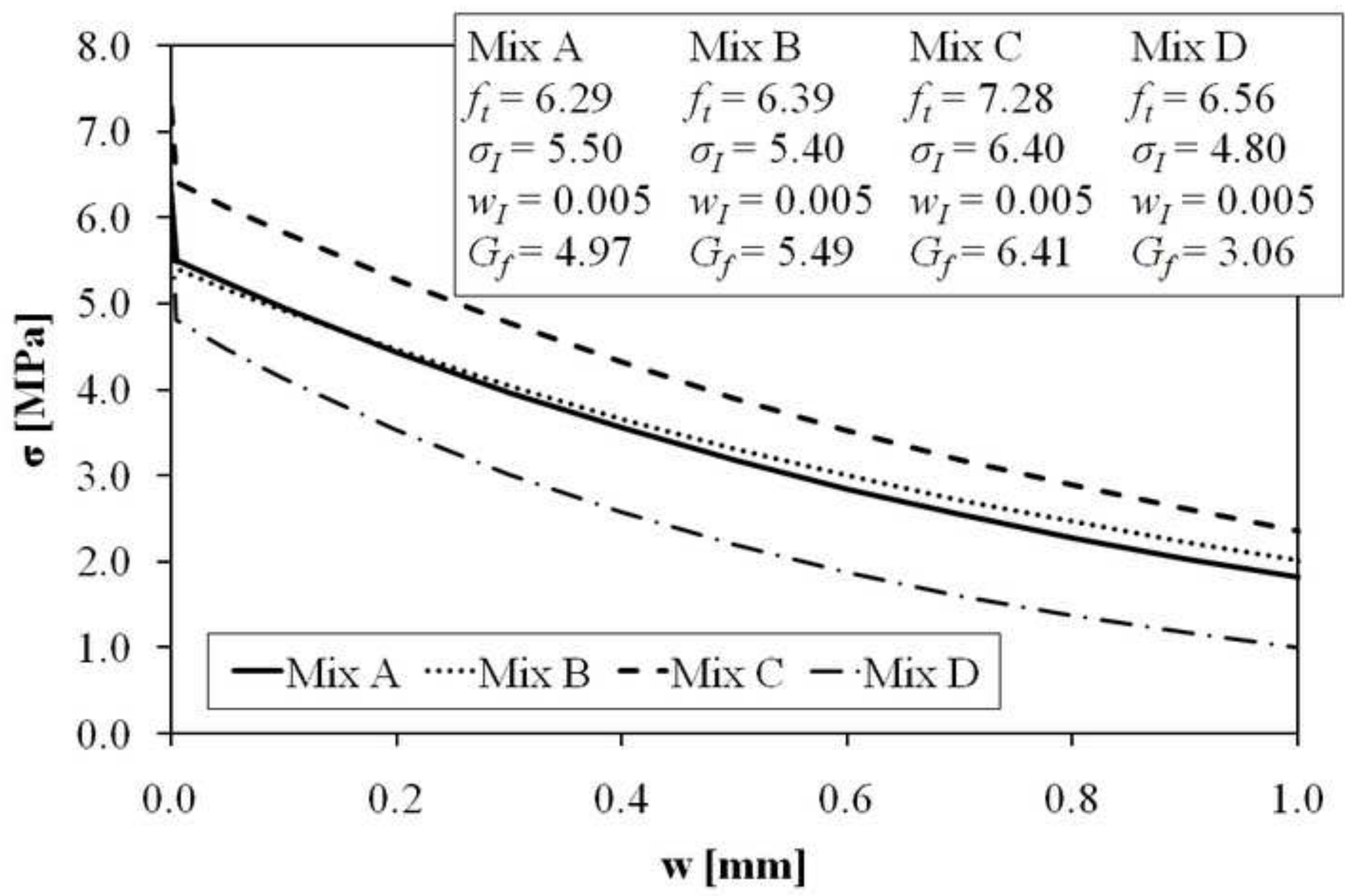


Click here to download high resolution image
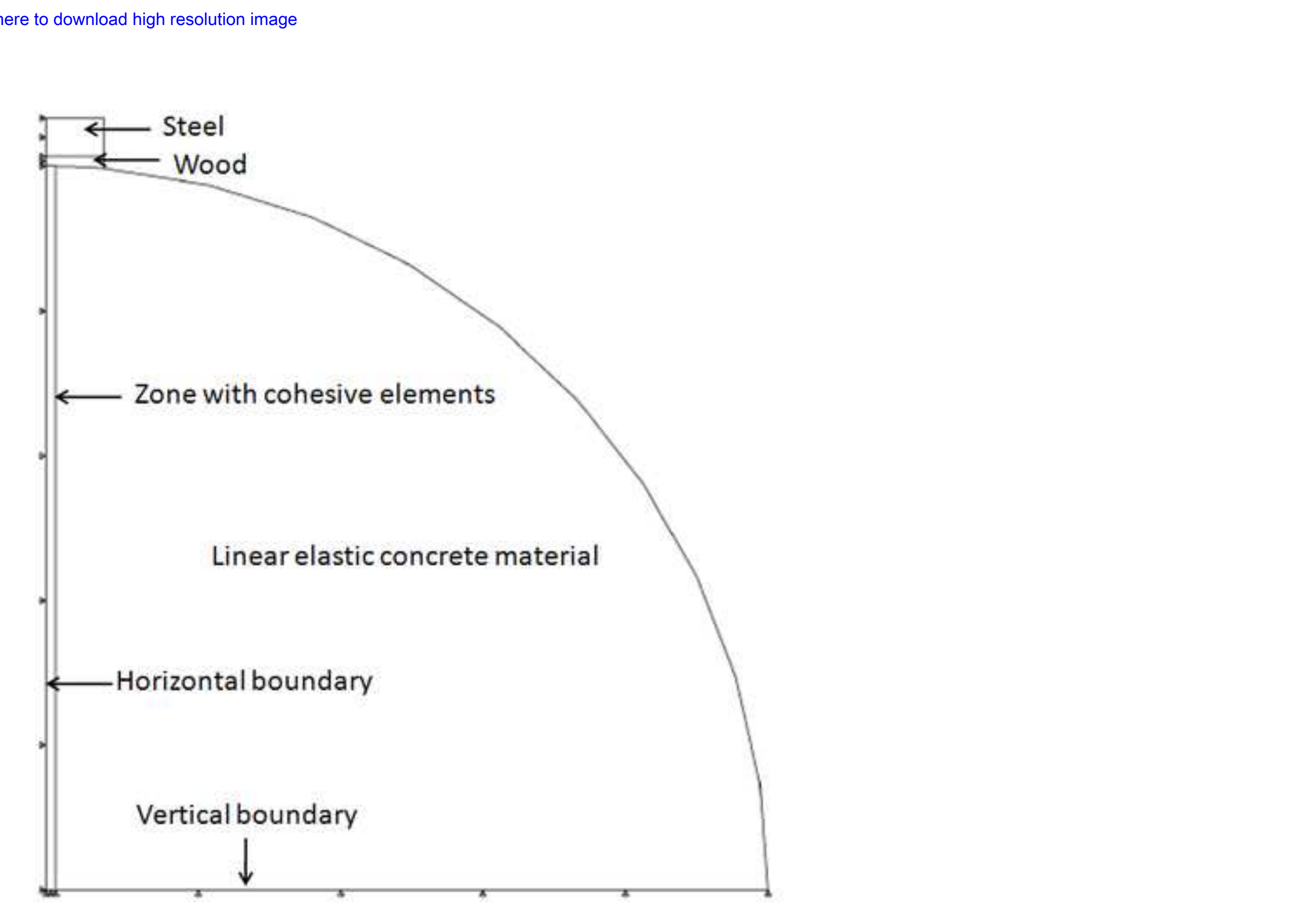

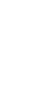
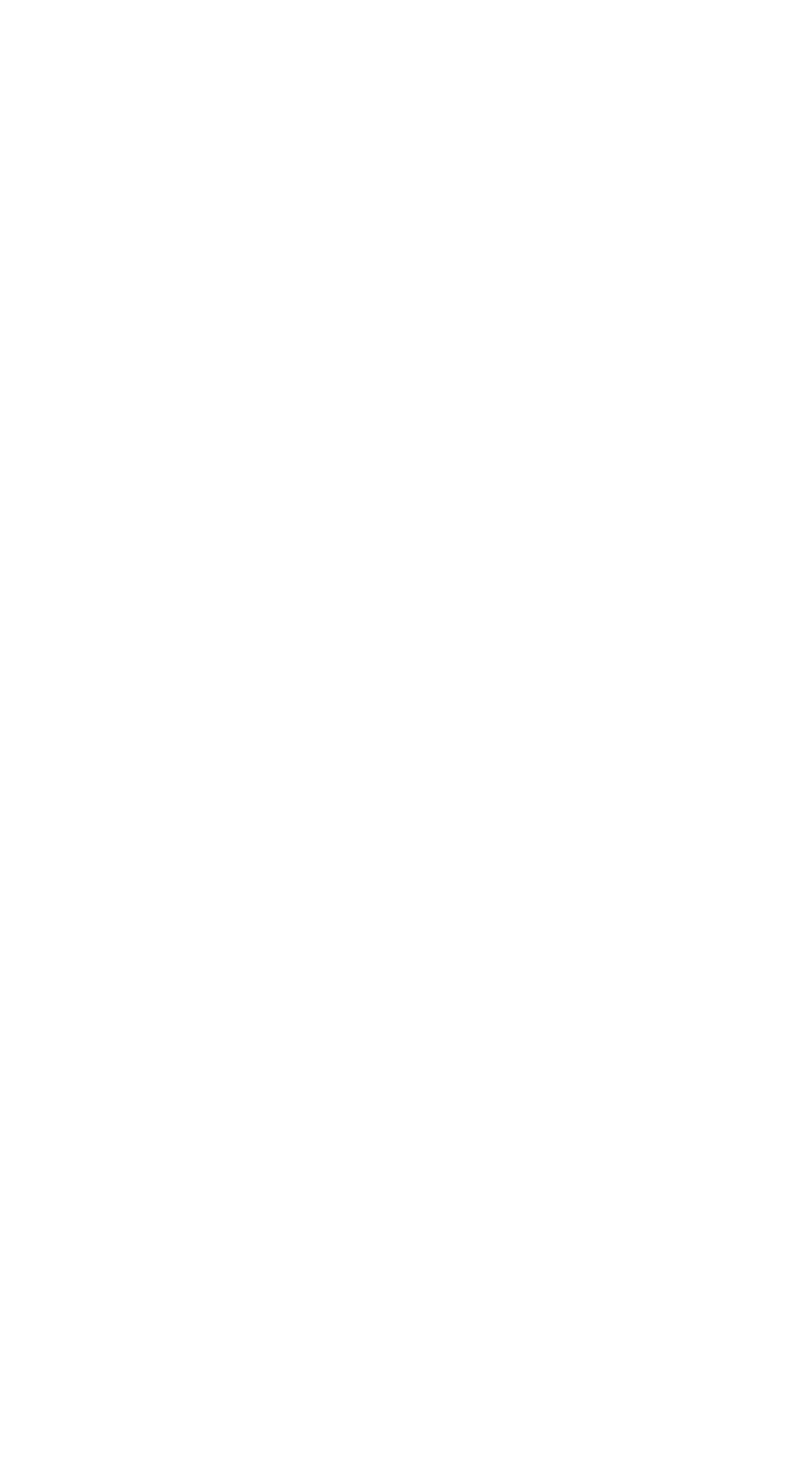

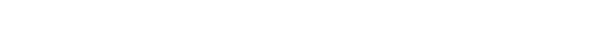

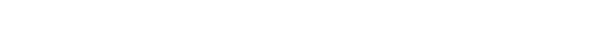

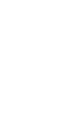

-

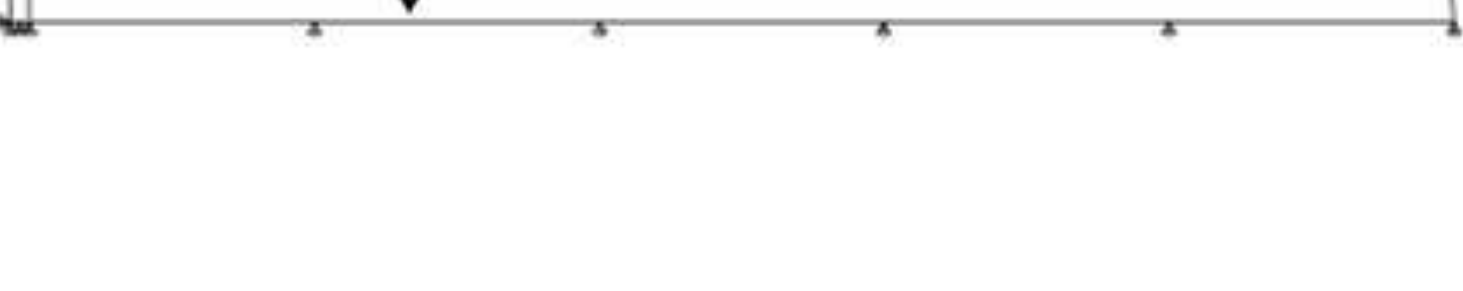




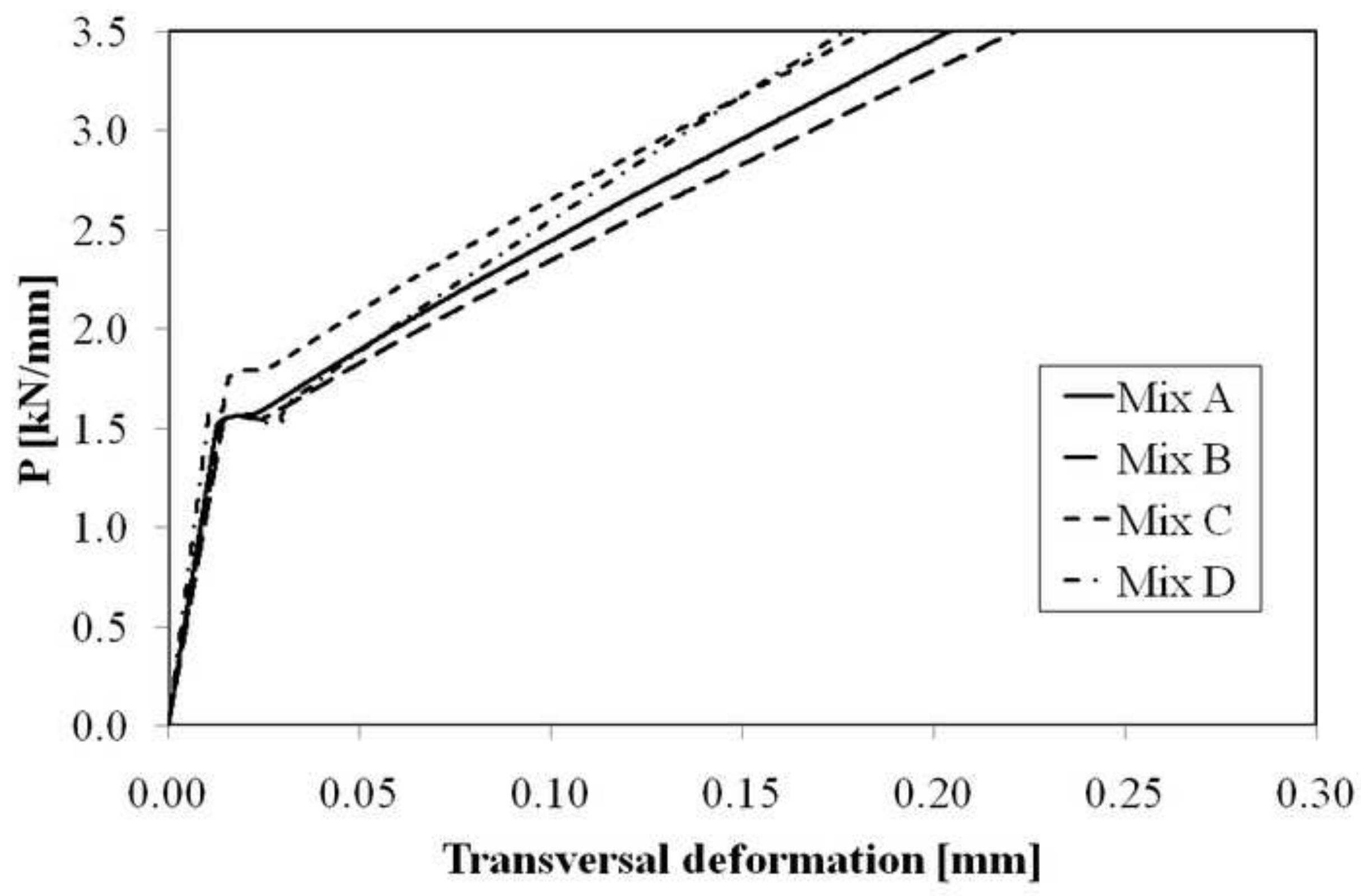


Click here to download high resolution image
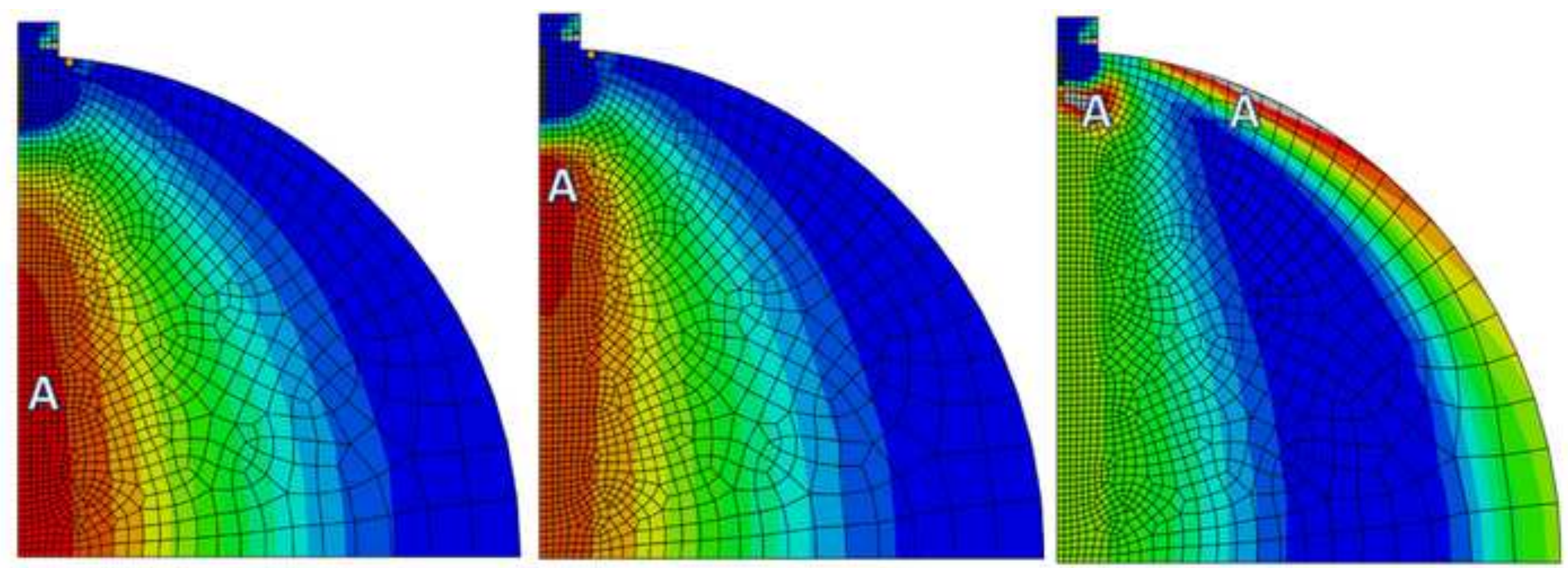